\title{
Sentidos e significados da participação de torcedores violentos de futebol do Rio de Janeiro
}

http://dx.doi.org/10.11606/1807-5509201800030405

\author{
Diego Luz MOURA* \\ Marcelo dos SANTOS* \\ Marcelo Moreira ANTUNES ${ }^{* *}$ \\ Alexandre Jackson CHAN-VIANNA*** \\ Roberta MÉLO* \\ Bruno Otávio Lacerda de ABRAHÃO* \\ *Universidade Federal \\ do Vale do São \\ Francisco, Petrolina, \\ PE, Brasil. \\ **Universidade do \\ Estado do Rio de \\ Janeiro, Rio de \\ Janeiro, RJ, Brasil. \\ ${ }^{* * *}$ Universidade de \\ Brasília, Brasília, DF, \\ Brasil.
}

\section{Resumo}

0 tema do artigo é a violência no futebol. A ideia central é compreender as razões e significados que os torcedores violentos atribuem às suas ações dentro e fora dos estádios. Os dados foram produzidos a partir de entrevistas com os próprios torcedores violentos. Foram postos em questão os conceitos de processo civilizatório e o esporte como espaço de reserva da violência controlada. Os resultados apontam para um perfil de torcedores e suas razões de serem violentos que contrariam o senso comum. A participação em uma rede de relacionamentos e a busca da excitação nas brigas ao invés de no jogo de futebol regem a motivação desses torcedores.

PalavRas-Chave: Futebol; Violência; Torcedores.

\section{Introdução}

A violência nos estádios de futebol é um fenômeno que vem ocorrendo de modo constante nas últimas décadas e tornando-se uma questáo de segurança pública. Aqueles que acompanham o futebol se recordam de cenas de violência envolvendo torcedores do Coritiba Foot Ball Club, no estádio Couto Pereira, diante do rebaixamento da e'quipe à Série $\mathrm{B}$ na edição do Campeonato Brasileiro de 2009 e da briga entre os torcedores do Clube Atlético Paranaense e do Clube de Regatas Vasco da Gama, em Joinville, na partida que culminou no rebaixamento deste último para a Série B, em 2014. Estes são exemplos recentes da manifestação da violência física entre os torcedores brasileiros.

Tais cenas ganharam o noticiário esportivo e foram amplamente divulgadas pela mídia impressa e televisiva. Assistidas e lidas pela população em um contexto que o Brasil se encontrava às vésperas de sediar uma Copa do Mundo Fifa de Futebol masculino de 2014, tais cenas ameaçavam o projeto do Brasil de mostrar-se um país civilizado. Neste sentido, os mecanismos de controle dos impulsos agressivos da população se veem sob suspeita do mesmo modo da capacidade da defesa nacional em garantir a segurança de visitantes estrangeiros.

Sendo o futebol uma modalidade rentável e lucrativa, a violência é um dos fatores que pode comprometer os investimentos realizados por clubes, empresas e interessados neste esporte ${ }^{1}$. Por isso, sua presença contraria o ordenamento atual do futebol brasileiro, passando a ser o inimigo a ser combatido em virtude no projeto nacional que visa a reafirmar seu desenvolvimento náo apenas na dimensão política e econômica, mas também no plano dos seus valores e atitudes.

Investigar a violência remete a necessidade de lançar luz sobre a hooliganismo no futebol. DunNING ${ }^{2}$ ao analisar sociologicamente este fenômeno mundial o identificou como complexo e multilateral. Apontou que este termo é constantemente acionado pelos meios de comunicação para designar uma variedade de comportamentos relacionados à violência de várias ordens relacionados ao futebol. Investigar o hooliganismo no futebol nos aproxima 
dos torcedores organizados que são apontados muitas vezes pelos meios de comunicação como responsáveis por estes enfrentamentos.

As imagens e as interpretaçôes veiculadas enfatizam a transgressáo e a agressividade como características centrais desses agrupamentos. $O$ futebol, para estes torcedores organizados, como observou ToLEDO ${ }^{3}$, é parte constitutiva de um estilo de vida próprio. Ao assumirem preferências pelo clube do coraçáo, por símbolos e marcas de cada torcida organizada, estes indivíduos referendam condutas específicas diante de outros grupos no cotidiano.

Ao longo do Século XX o futebol consolidouse como o esporte mais popular do país e passou a atrair cada vez mais torcedores demandando a construção de novas instalações. A participação mais intensa dos torcedores durante os jogos veio através da criação das torcidas uniformizadas, surgidas no Rio de Janeiro em 1942 com a Charanga do Flamengo no Rio de Janeiro ${ }^{3}$.

A estrutura básica destas organizaçôes consiste no comando de uma pessoa conhecida como "chefe de torcida", que agrupa em torno de si dezenas de simpatizantes, sendo as mesmas vinculadas aos clubes através de políticos, dirigentes ou funcionários. Esses vínculos políticos com os clubes e seus dirigentes fez com que alguns torcedores se opusessem a tal modelo por considerar que ele inibiria possíveis críticas, cobranças e expressões como vaias. Essa oposição fez surgir um novo tipo de torcida e de torcedor, as torcidas jovens com o desejo de terem independência para se posicionarem criticamente quando necessário ${ }^{4}$.

De acordo com TeiXeira ${ }^{4}$, o surgimento das torcidas se deu além do incentivo ao time, constituindo-se também como forma de protestar frente ao clube. Este novo grupo de torcedores já não dependia tanto dos clubes, pois eles se mantinham financeiramente com vendas de camisas, meias, bonés, e outros acessórios com o emblema da equipe e da torcida. Por meio desta nova configuração, passou-se a cobrar mensalidades dos sócios e a organizar caravanas para viajar a outros estados.

Nos jogos considerados clássicos ${ }^{a}$ há uma maior possibilidade de ocorrência de violência entre torcidas. Os mais variados motivos são relatados para explicar o acontecimento de brigas ${ }^{5}$ : erros de arbitragens, má administração dos clubes, corrupção de dirigentes, provocações de adversários e etc. Num diálogo entre um repórter e um torcedor envolvido em uma briga em São Paulo durante uma partida, o torcedor respondeu ao ser indagado sobre sua opinião acerca do confronto que gosta da briga apenas para chegar em casa e vangloriar-se com os amigos pelo fato de ter confrontado com seu "inimigo", e que não sendo seu amigo, se alguém morrer, tudo bem ${ }^{1}$. Um novo arranjo neste cenário são as brigas agendadas pela internet $\mathrm{t}^{\mathrm{b}}$. Estes confrontos buscam locais em que o policiamento não consegue estar presente para a contençấo da violência.

Estes fatos nos levaram a utilizar a categoria "torcedores violentos" para designar os indivíduos que apontam as brigas como principal motivo para comparecerem aos estádios. Outra particularidade do cenário contemporâneo em que ocorrem essas práticas de violência diz respeito ao papel da mídia. Estamos nos referindo, afinal, a um momento social no qual nossas relações são fortemente mediadas por imagens, conforme sugere DEBORD ${ }^{6}$ em suas consideraçóes acerca da "Sociedade do Espetáculo" $\mathrm{e}$, de fato, as relaçóes sociais que constituem nosso objeto primordial de análise têm um apelo imagético que se revela nos impactos causados pelas transmissóes das cenas de violência pela mídia.

De acordo com VIGARELLO ${ }^{7}$, o esporte se tornou um dos mais importantes espetáculos no século XX, contando fundamentalmente com as transformaçóes nas "maneiras de ver" trazidas pela televisão e cinema. Os avanços tecnológicos e as formas de comunicação e sociabilidade características do uso da internet têm reconfigurado o alcance dos espetáculos esportivos. Neste contexto, a mídia televisiva e impressa, as redes sociais, dentre outros veículos midiáticos, podem ser entendidos como importantes ferramentas na busca pela visibilidade e afirmação do "ser violento".

Ao mesmo tempo, as exibições midiáticas de tais episódios de violência não são isentas de discursos valorativos e moralizantes (que orientam comportamentos individuais e coletivos) enfatizando, por vezes, seus prejuízos para a ordem social. Neste sentido, é importante percebermos de que modo tais veículos participam das significaçóes e sentidos que estes torcedores buscam dar às suas práticas.

Todavia, ao estudar este tema náo podemos generalizar que todas as torcidas e torcedores que participam destes agrupamentos agem ou organizam atitudes violentas nos estádios. LiMA, Moura e Antunes ${ }^{8}$ acompanharam durante um ano uma torcida do flamengo que tinha como principal característica prezar pela não violência e demonstraram os diferentes ritos de sociabilidades que são construídos entre as torcidas. Contudo, há indivíduos que participam das torcidas que possuem como principal objetivo são as brigas e conflitos. 
Neste sentido, na busca do ideário da erradicação da violência dos estádios é salutar questionar: quais os sentidos e significados que os torcedores reconhecidos como violentos atribuem às suas açóes? Afinal, é insuficiente pensar em intervençóes de segurança e açôes educativas, se desconhecemos as motivaçôes dos torcedores para as brigas e enfrentamentos corporais. Dessa forma, o objetivo deste artigo é compreender os sentidos da participação de torcedores violentos em estádios de futebol do Rio de Janeiro.

\section{Metodologia}

Realizamos uma pesquisa de campo com integrantes de torcidas organizadas das grandes equipes do Rio de Janeiro. Utilizamos a técnica de bola de neve com saturação". Fomos ao encontro desses integrantes que reconhecidamente se envolvem ou se envolveram em brigas de torcidas. Esta técnica de pesquisa tem como objetivo solicitar que os próprios informantes indiquem os próximos a serem entrevistados, formando uma espécie de teia de relaçóes, que termina quando os dados começam a se tornar saturados.

O procedimento da coleta se deu da seguinte forma: iniciamos a pesquisa com um informante que era próximo a um dos autores e que se autointitulava como violento. Ao final da entrevista, solicitamos que este fornecesse contatos de indivíduos que ele soubesse que possuía o perfil da pesquisa, independente da torcida de que participavam. $\mathrm{O}$ mais interessante desta etapa

\section{Resultados}

Não foi possível identificar uma regra sobre o início de participação nas torcidas, pois uma parte iniciou a ida ao estádio como frequentador de uma torcida, enquanto outra parte havia ido já na infância, filiando-se às torcidas posteriormente.

Ao questionarmos os torcedores entrevistados sobre sua primeira participação em brigas de torcidas e encontramos uma série de motivações relacionadas ao pertencimento a tais agrupamentos.

"A primeira briga a gente nunca esquece né! Estava no ponto de ônibus nem era de torcida organizada, simplesmente estava com a minha camisa. O pessoal tomou a minha camisa e me espancou, mas hoje eu dei a volta por cima, estou aí nas torcidas organizadas e o que vier é lucro" (Informante 2).

"Era novo na torcida, jogo do [...] e [...], estava indo encontrar a galera da $[\ldots]$ e o pessoal da foi perceber que os informantes conhecem alguns dos torcedores violentos das demais torcidas.

Entrevistamos um total de 9 torcedores de diferentes torcidas organizadas, todos do sexo masculino e da faixa etária de 22 a 32 anos. Isso nos mostrou que não apenas jovens, mas também homens adultos são adeptos de práticas de violência entre torcidas. Os encontros foram realizados em locais públicos agendados anteriormente com os entrevistados. As entrevistas foram transcritas e analisadas através de uma análise interpretativa dos dados. As entrevistas foram realizadas no primeiro semestre de 2011.

Quanto à escolaridade, todos possuem o ensino médio concluído, sendo 6 com ensino superior completo, 2 com ensino superior em andamento e 1 com formaçáo técnica. No momento da pesquisa todos estavam empregados e alguns inclusive atuantes em negócios próprios ou de empresas da família.

[...] me enquadrou no Largo do Machado. Eles tomaram minha camisa e me deram uns tapas, dei mole porque passei na área dos caras de camisa" (Informante 9).

"A primeira, foi aqui na área mesmo quando a gente foi cobrar um maluco da [...]. Eles iam fazer uma reuniáo, aí a gente foi lá de bicho, foi meio loucura, mas eles "peidaram" na primeira porrada já ganhei um nome na torcida" (Informante 6).

"No primeiro dia que fui já briguei, briguei não né, tomei a camisa de um maluco da [...]. Quando cheguei no maraca com a camisa do moleque e os caras colocaram fogo nela. Geral falando que eu representei, foi muito bom!" (Informante 7).

Podemos observar que a primeira briga é compreendida como uma espécie de ritual para os neófitos, pois a partir deste primeiro momento 
eles se reconhecem como verdadeiros integrantes de sua torcida. Quando os informantes relatam sobre seus principais feitos na torcida, afirmam que estes serviram para fidelizá-los às mesmas. As açôes estão relacionadas com agressóes à policiais, roubos de bandeira, espancamentos e invasão de estádios.

"Pô! Graças a Deus eu nunca sofri. O único prejuízo que eu tenho foi uma briga na radial oeste que eu ganhei uma madeirada com prego no joelho, mas tirando isso aí, graças a Deus eu nunca sofri nenhum prejuízo e também não quero nem sofrer" (Informante 4).

"Uma vez caí na porrada com um cara e ele estava armado. $\mathrm{O}$ desgraçado ainda deu 2 tiros pra cima de mim, eu consegui correr, mas depois ainda voltei enfiei a porrada nele e tomei a arma. Só voltei porque era inimigo e não posso dar mole pra eles” (Informante 9).

“Já em uma briga, a gente estava dentro do ônibus passando pela presidente Vargas do lado da torcida da [...] que começaram a apedrejar. Tivemos que correr pra dentro do metrô e teve até um amigo nosso que abriu a testa porque bateu no paralelepípedo do metrô" (Informante 1).

"A maior loucura, cara, parti pra cima do policial, mas o outro veio por trás e me deu um tiro de borracha” (Informante 2).

Estas situaçóes, por vezes, são extremas a ponto de culminar na prisão dos envolvidos. Do total de 9 informantes, 6 já foram presos e 3 apontam que por pouco não o foram:

"Já fui preso esse ano, caso recente né [...], quando a gente foi dar um ataque em Botafogo na torcida rival e deixamos um deles lá no hospital todo ferrado e fomos presos na entrada do Túnel Santa Bárbara. Cara, quando a ficha caiu naquele primeiro momento estávamos com o sangue quente, tudo era novidade estava todo bobo, vamos ganhar moral na torcida. Mas no decorrer dos 17 dias que a gente ficou preso na Polinter ${ }^{\mathrm{c}}$, a ficha foi caindo, aí você vai vendo que a verdade é loucura, num vale nada. Você não ganha nada com eles entendeu? a não ser moral. Moral eu vou querer pra que? Não ganho dinheiro, ingresso de vez em quando, entendeu? É o que falo meu irmão: pra fazer, pra entrar na torcida, você tem que gostar mesmo, se for pra você depender de dinheiro, de ganhar alguma coisa em troca você está fudido!, se não for da patotinha, da diretoria, não vai ter nada" (Informante 4).

"Na primeira, foi novidade, até fiquei tranquilo, porque era réu primário, sabia que não ia dar em nada. Na segunda vez, realmente a ficha caiu porque já tinha sido preso, estava com medo por ser reincidente e só fui porque queria devolver o prejuízo da garrafada que levei. Também fiquei mal e bem ao mesmo tempo, porque estava ao lado de amigos na cela e vi que estavam do meu lado. Geral não diz que amigo mesmo não é aquele que separa a briga, mas sim o que já chega dando voadora? Então, deram voadora, cadeirada, foram presos, tudo comigo (Informante 7).

Embora o medo esteja presente, o prazer pela busca da afirmaçáo da violência a favor do seu grupo acaba sendo maior, fazendo com que os mesmos enfrentem os riscos e realizem o confronto. Outro ponto importante de se observar é a reflexão que realizam na prisão. Entretanto, esta reflexão não é garantia de que não realizarão novamente as práticas de violência.

Quando questionados sobre o que sentem quando brigam, estes revelaram uma lógica de violência que é descolada do futebol, onde a briga é o principal atrativo:

"Só entrei na torcida por isto, nem me ligo muito em futebol, mas como sempre fui pra baile de corredor $^{\mathrm{d}}$ e os amigos eram de torcida, aí comecei a ir. Eu gosto e gosto muito" (Informante 6).

"Eu sempre senti medo, na verdade. Depois que você sai ganhando, que seu ego vai lá em cima, geral falando de você, na hora bate medo de tudo, depois vem a recompensa" (Informante 8).

"É aquele alívio de estresse de semana né. Eu passo a semana toda trabalhando... aí quando você pega um 'bunda rachada', você tira todos os estresses. O foda é quando apanha, aí é vergonha no trabalho" (Informante 2). 


\section{Discussão}

Todos os torcedores entrevistados são do sexo masculino. Este dado revela uma tendência no perfil de torcedores autodeclarados violentos. Entretanto, não podemos generalizar que tal tipo de prática é restrita aos homens. Apenas neste momento não foram indicadas mulheres que participam de atividades de violência.

O predomínio de homens como torcedores violentos pode ser explicado por Elias e DuNNING ${ }^{10}$ ao apontar como o esporte se construiu como um espaço de reserva masculina. De acordo com os autores, algumas práticas como o futebol e o rúgbi, desde sua origem tornaram-se um espaço de reserva eminentemente masculina pela representaçáo da guerra entre equipes e pelos altos índices de violência e agressividade.

Sendo o gênero uma construção social, o campo de futebol é um espaço da construção da identidade do "ser homem". No caso do Brasil, o futebol tornouse espaço da afirmação de masculinidade que se opera, sobretudo, pelo uso da força e da virilidade. Entretanto, neste momento parece haver um recredescimento das tentativas de desmasculinizar os esportes de confronto e superar as forças da reserva. Isto pode ser observado pela entrada maciça das mulheres nos esportes de confronto.

Todavia, se por um lado esta força de desmasculinizaçáo adentrou os esportes de confronto onde a agressividade é evidenciada de forma mais explicita, por outro lado, parece que na violência praticada pelas torcidas ainda há indícios que sugerem uma predominância masculina, onde se reafirmam características que são culturalmente mais relacionadas aos homens.

Silva, Souza Neto e Campos ${ }^{11}$ chamam atençáo para o fato de que o futebol, enquanto possibilidade de lazer, náo ocorre somente dentro das quatro linhas que delimitam o campo. Se for levado em consideração o âmbito da festa, do encontro, das redes de sociabilidade nas arquibancadas há uma grande quantidade de pessoas contribui para a realização e a beleza desse espetáculo esportivo vivenciado no espaço/tempo de lazer.

Neste sentido, parece que tais práticas de violência dizem respeito a uma "inversão" da forma de experimentar os sentimentos, emoçóes, prazer e satisfação. $\mathrm{O}$ ato de violência destes torcedores nos coloca diante da constatação que se envolver em situaçóes de enfrentamentos e violência, garante prestígio e visibilidade junto à torcida ao mesmo tempo que proporciona prazer, satisfação e excitação para aqueles torcedores. No mesmo sentido, TEIXEIrA ${ }^{12}$ aponta que o envolvimento nas brigas é entendido como uma obrigaçáo moral.

DunNing ${ }^{2}$, com preocupações próximas das nossas, questionou: "quem são os hooligans e porque eles se comportam dessa maneira” (p. 58). $\mathrm{Na}$ Inglaterra foram apontadas 5 interpretações populares pelos meios de comunicaçáo, políticos e membros da populaçáo em geral. Sáo elas: consumo excessivo de álcool; incidência da violência em campo, durante o jogo; desemprego; melhores condiçóes de vida e permissividade. $\mathrm{O}$ autor apresenta citaçóes literais que lançam luz sobre a características dos valores e motivações de hooligans ingleses.

Recordando emoçóes vividas durante seus dias de ativo envolvimento hooligan, nos anos de 1960, Taylor escreveu ao The Guardian em 1984, o seguinte: "a emoção da batalha, o perigo, o aumento da atividade do corpo e da mente bem como da adrenalina correndo, o medo e o triunfo da superação. Hoje em dia, quando se inicia uma confusão em um jogo eu me sinto vivo e fico perto de me envolver. Eu náo posso esquecer dos perigos, das lesóes físicas e dos processos penais, mas eu os ignoro"

DunNING ${ }^{2}$ apresenta outras declarações cujo conteúdo revela que para a maioria dos homens jovens envolvidos, os combates entre hooligans no futebol são basicamente "associados à masculinidade, à disputa territorial e à excitação. Para eles, a briga é uma fonte central do significado, status ou reputação, além de prazerosa excitação emocional” (p. 65).

ReIs 5 chamou atenção para o fato de "explosóes", na concepção de Dunning, Murphy e Willians ${ }^{13}$, explicariam o hooliganismo. Os jovens oriundos da classe trabalhadora encontrariam no contexto do futebol um espaço privilegiado para brigas, agressóes e outras formas de violência que serviriam como um meio de afirmaçáo pública de masculinidade no seu meio social.

Também nessa direçáo Pimenta ${ }^{1}$ aponta, no trabalho de Norbert Elias, a questão da excitação e do prazer pela prática de atos que fogem aos padróes de controle estabelecidos pelas sociedades capitalistas. Ao mesmo tempo, não podemos desconectar tais experiências afetivas das excitaçóes e estímulos provocados pela própria sociedade que as reprime.

Pimenta ${ }^{1}$ analisando os discursos das autoridades esportivas e dos torcedores, aponta que a violência 
geralmente é explicada pelas seguintes justificativas: má distribuição de renda, ausência de expectativa de futuro entre os jovens, efeitos da pobreza, falta de emprego, miséria generalizada, entre outros. Tal linha de pensamento corrobora a ideia do senso comum de que apenas indivíduos menos favorecidos socialmente praticam violência.

Porém, não parece correto generalizar que apenas escolaridade, renda e classe social, seriam os únicos motivos da geração da violência. Podemos observar que todos os informantes entrevistados possuem alto nível de formação, bons empregos, acesso à universidade, poder aquisitivo, e que moram em área considerada nobre da cidade do Rio de Janeiro. Dessa forma, não é possível atribuir somente às classes menos favorecidas a responsabilidade pelas práticas da violência ${ }^{14}$.

Gregório e Celess ${ }^{15}$ apontam que os motivos pelos quais a violência dos hooligans é desencadeada são múltiplas e que não pode ser enquadrada em padróes ou regras gerais. Da mesma forma, também não é possível perceber uma relação entre o tempo que participam de torcidas e o início das práticas de violência, pois alguns ingressaram nos grupos anos antes começarem a buscar as brigas e outros movidos pelo desejo da violência. Tal perfil é semelhante ao descrito por TeIXeIRA ${ }^{4}$, que nem todos os torcedores são atuantes e a rotatividade é muito grande e que além daquele grupo fiel, existem aqueles que atuam durante certo tempo e depois desaparecem. Há ainda os que acompanham todo o campeonato, saem e depois retornam ${ }^{3}$. Em outras, a rotatividade de indivíduos dentro das torcidas organizadas é intensa e deste modo coexistem diferentes perfis e formas de pertencimento a uma mesma torcida.

A primeira briga é narrada como um rito de passagem, um acontecimento revelador de uma nova etapa de vida ${ }^{16}$. As histórias de confronto são contadas de forma contagiante, exaltando o poder da torcida e a força que possuem. Os torcedores afirmam que foi mediante uma postura violenta em uma situação de confronto que ganharam reconhecimento ou um "nome na torcida". É através das brigas que se reforça mutuamente uma identificaçáo dos componentes da torcida com os neófitos e um sentimento de pertencimento destes com a torcida.

TeIXeIrA ${ }^{12}$ afirma que compartilhar do risco, do perigo, da imprevisibilidade é um eixo norteador dos processos de sociabilidade que se estabelece no grupo de torcedores. Os valores que subjazem a socialização desses torcedores são os de defesa da honra a todo custo, o que se desdobra para além das arquibancadas, permeando os entornos dos estádios, bares e ruas adjacentes. Desse modo, levando a violência também para fora dos ambientes de jogo.

Construir identidade a partir de um desvio da norma não é privilégio dos torcedores violentos. Chan-VIanna ${ }^{17}$ observou mulheres praticantes desse esporte e apontou que as jogadoras se reconheciam à margem do modelo de feminilidade do local e o futebol.

Não se trata de afirmar que torcedores se tornam violentos porque participam de torcidas organizadas ou participam destas porque são violentos. O importante é destacar que a atitude de enfrentamento a outra torcida agrega valor de pertencimento ao neófito, bem como condecora com prestígio e louvor junto aos veteranos.

Se, como sugere $V_{\text {eLHO }}{ }^{18}$, a violência possui uma lógica própria com suas razóes, no caso dos torcedores do futebol as ações violentas têm componentes de afirmação de uma identidade coletiva. Assim, ser violento os inclui não apenas na própria torcida, mas em todas outras, amigas ou inimigas, que formam uma mesma rede de relacionamentos e pertencimento. A violência dos torcedores de futebol tem contornos de afirmação identitária.

Por outro lado, Hollanda ${ }^{19}$ sugere que a violência no futebol se dá quando há uma espécie de "escoamento de tensóes", que pode explicar o sentido de fatores do cotidiano do torcedor se refletir no ato de torcer. O gosto pelo futebol e pela sua equipe é relegado a um segundo plano, pois em todas as análises apresentadas não há relatos de brigas causadas pela defesa de seu time. Apenas ocasióes de conflitos gerados entre integrantes de torcidas consideradas "inimigas". O futebol com suas regras civiliza a violência e que as torcidas, pelo menos uma parte delas, organiza um novo jogo com regras antigas que recuam no processo civilizatório.

A prisão mostra coragem, ousadia, amor à torcida e aumenta o prestígio e status desses torcedores dentro de suas torcidas ao menos pelo grupo que permanece e se conforma com as normas tácitas da torcida. Tais atitudes são encorajadas entre grupos de torcedores que consideram uma conquista heróica e faz com que a violência se legitime. Além disto, o fato de ser preso constrói relaçốes mais sólidas de sociabilidade. Todavia

O cenário de tentativas do Estado (representado pela Polícia) de controlar tais "excessos" leva-nos a outras observaçóes a respeito da desordem social que se revela nas práticas destes torcedores. Podemos compreendê-las como um tipo de desvio que, conforme VIGARELlo ${ }^{7}$ (p.478), nos faz constatar até 
que ponto "o direito e o poder público são atingidos e não somente a sociedade esportiva”.

\begin{abstract}
Se o espetáculo foi lentamente se instalando no mundo esportivo, é inegável que triunfou aí, misturando uma sutil dosagem de fascinação pela performance, de investimento indenitário, de invenção de mercado. O gigantismo ininterrupto do esporte, sua visibilidade em todas as latitudes, sua onipresença na mídia inevitavelmente suscitariam, em contrapartida, uma tendência à transgressão. Nenhuma surpresa quanto a isto: na paixão é necessariamente, aqui, a do excesso, como a única resposta possível é necessariamente a da lei. Resposta que tira toda a sua força do recurso ao poder público muito mais que à própria instância esportiva ${ }^{7}$ (p.480).
\end{abstract}

WILLING ${ }^{20}$, analisando as práticas de participantes de esportes de aventura em situações de risco extremo, apontou que passar momento de vulnerabilidade juntos fazia com que os atletas construíssem fortes redes de sociabilidade. No caso destes torcedores, serem presos junto com os companheiros de torcidas permite dar mais sentido de pertencimento à torcida e estabelecer de amizades mais sólidos. O Estado, por sua vez, não pode deixar de prendê-los.

Todavia, os torcedores, ao menos uma parte deles, reconhecem a gravidade de algumas açóes. PALHARES e Schwartz ${ }^{21}$ analisando o discurso de torcedores apontam que reconhecem esses tipos de violência e assumem que as torcidas, muitas vezes, extrapolam os limites do bom senso.

Este artigo procurou compreender significados da violência para os torcedores violentos e o sentido que eles atribuem às suas ações. Através dos dados coletados nos relatos dos atores sociais, percebe-se que os torcedores violentos seguem uma corrente de tradição ao se apropriarem do futebol, um esporte de confronto, como espaço legitimado e organizado para a fruição da agressividade no processo civilizatório em nossa sociedade.

Ao contrário do que acredita o senso comum, os dados deste estudo revelam que os "torcedores violentos" são homens, jovens adultos, escolarizados, empregados e de classe média. As imagens televisivas que aterrorizam aqueles que aspiram por um mundo pacífico e civilizado não podem ser atribuídas aos menos favorecidos ou aos esquecidos pela sociedade.

Da mesma forma, as brigas não estão associadas à paixão/ódio pelos times, mas à excitação pelo perigo e a afirmação da masculinidade que encontram eco no pertencimento a uma rede de relacionamentos que premia aqueles que enfrentam as ordens instituídas como policiais e a cadeia ou espaços da vida cotidiana e organizada como o campo de futebol ou a praça pública. Assim, constitui-se uma identidade que os engaja em uma rede de relacionamento.

De acordo com Elias e DunNing ${ }^{10}$ o esporte, principalmente os de confronto, tornou-se o principal espaço para utilização da violência legítima. Esta violência em outros períodos era utilizada nas guerras e conflitos. Na medida em que há uma reorganização da estrutura social, a violência começa a aparecer a partir das mudanças no processo civilizatório do século XIX em diante.

O futebol acaba por ser um local privilegiado para a utilização dessa violência até então controlada, que atua como uma mimese da guerra. Entretanto, Elias comenta sobre a mimese pacífica e não a briga corporal violenta com risco de vida. Desta forma, o caso da violência com as torcidas organizadas possibilita refletir como o futebol com suas regras civiliza a violência, mas que as torcidas, pelo menos uma parte delas, aponta dos limites da civilização quando se trata de partidas de futebol.

As brigas de torcida tornam-se um tempo-espaço de fruição dissociado das vidas literais dos seus participantes, que expressam as individualidades reprimidas contra aquilo que o consenso da sociedade reconhece como próprio de um comportamento adjetivado como civilizado. Com regras e éticas próprias, os torcedores violentos criam um novo jogo à margem do futebol. Igualmente excitante, imprevisível, desafiador e contestador os enfrentamentos entre torcedores são mediados pelo futebol, mas a disputa é de outra ordem: preocupa-se com a aproximação da identidade da torcida aos códigos da virilidade e masculinidade e angariar capitais para ser reconhecido junto aos pares como alguém distintivo dentre da torcida.

Diante desse quadro, o Estado, como portador da utilização legítima da violência deve buscar saídas para manter a civilidade através de planejamento e outros artifícios para a contençáo da violência. Portanto, é imperativo que o Estado continue atuando de forma a controlar esta violência, considerando que a violência possui suas próprias lógicas. Por outro lado, a sociedade organizada deve também constituir espaços alternativos com cunho pedagógico para que os torcedores expressem e reflitam sobre sua agressividade e privilegiem outras formas mais nobres de expressão. 


\begin{abstract}
Senses and meanings of the participation of Hooligans in Rio de Janeiro footbal

The theme of the article is football violence. The main idea is to understand the reasons and meanings that hooligans give to their own actions inside and outside the football field. Data were collected from interviews with hooligans. The concepts of the civilizing process and sport as a reserve space of controlled violence were placed in question. The results indicate that the profile of hooligans is different than the imagined by common sense. Participation in a network of relationships and the seek for excitement in fights instead of the in football game seem to govern the motivation of those fans.
\end{abstract}

KEYWORDS: Soccer; Violence; Hooligans.

\title{
Notas
}

a. O clássico na linguagem futebolística é o jogo que reúne duas grandes equipes do mesmo Estado ou região.

b. De acordo com a PM de São Paulo, uma briga ocorrida no dia 25/03/2012, entre torcidas de Corinthians e Palmeiras antes da partida entre essas equipes, foi marcada pela internet através de redes sociais. $O$ confronto teve a participação entre 500 1000 torcedores segundo a Polícia e resultou na morte de um torcedor do Palmeiras. - http://globoesporte.globo.com/sp/ futebol/campeonato-paulista/noticia/2012/03/briga-entre-torcedores-de-palmeiras-e-corinthians-teve-entre-500-e-mil.html

c. Departamento de Polícia Interestadual, que registra, prende e atua em crimes parecidos com os investigados pela Polícia Federal, como os de envolvimentos mais graves de brigas de torcidas organizadas.

d. Baile de corredor eram festas funk, onde ocorriam confrontos entre grupos de áreas localizadas em diferentes locais do Rio de Janeiro.

\section{Referências}

1. Pimenta CAM. Violência entre torcidas organizadas de futebol. São Paulo Perspec. 2000;14(2):122-128.

2. Dunning, E. O hooliganismo como fenômeno mundial e europeu. PPGES - Revista do Programa de Pós-Graduação em Sociologia da UFPE. 2008;2(14):43-73.

3. Toledo LH. Torcidas organizadas de futebol. São Paulo: Vozes; 1996.

4. Teixeira RC. Torcidas jovens cariocas: símbolos e ritualização. Esporte e Sociedade. 2006;(2):1-26.

5. Reis HHB. Futebol e violência. Campinas: Autores Associados; 2006.

6. Debord G. A sociedade do espetáculo. Rio de Janeiro: Contraponto; 1997.

7. Vigarello G. O espetáculo esportivo das arquibancadas às telas. In: Corbin A, Courtine JJ, Vigarello G. Histórias do corpo: as mutaçóes do olhar: o século XX. Petrópolis: Vozes; 2009. p. 445-480.

8. Lima RL, Moura, DL, Antunes, MM. Ritos e sociabilidades no torcer coletivo: um estudo etnográfico em uma torcida do Flamengo. Licere. 2015;18(1):136-156.

9. Becker HS. Métodos de pesquisa em ciências sociais. São Paulo: Hucitec; 1993.

10. Elias N, Dunning E. A busca da excitação. Lisboa: Difel; 1992.

11. Silva SR, Souza Neto GJ, Campos PA. Lazer, torcidas e futebol. In: Isayama HF., Silva SR. Estudos do lazer: um panorama. Rio de Janeiro: Apicuri; 2011.

12. Teixeira RC. Futebol, emoção e sociabilidade: narrativas de fundadores e lideranças dos movimentos populares de torcedores no Rio de Janeiro. In: Esporte e Sociedade. 2013;8(21).

13. Murphy P, Williams J, Dunning E. O futebol no banco dos réus: violência dos espectadores num desporto em mudança. Oeiras: Celta Editora, 1993.

14. Souza ER. Masculinidade e violência no Brasil: contribuições para a reflexão no campo da saúde. Ciênc. saúde coletiva. 2005;10(1):59-70. 
15. Gregório GS, Celes LAM. Por que brigar? Uma perspectiva psicanalítica a respeito dos hooligans. In: Viana TC. Sobre Psicanálise, subjetivação, arte e cultura. Lisboa: Placebo; 2011. p. 181-194.

16. Turner V. O processo ritual: estrutura e antiestrutura. Petrópolis: Editora Vozes; 1974.

17. Chan-Vianna AJ. Meninas que jogam bola: identidades e projetos das praticantes de esportes coletivos no lazer. [Tese de Doutorado]. Rio de janeiro: UGF; 2009.

18. Velho G. Rio de janeiro: Cultura, Política e Conflito. Rio de Janeiro: Editora Zahar; 2007.

19. Hollanda BBB. Futebol, Arte e Política: A catarse e seus efeitos na representação do torcedor. Revista O\&S. 2009;16(48):123-140.

20. Willig, C. A Phenomenological investigation of the experience of taking part in 'extreme sports'. Journal of Health Psychology, Londres; 2008;13(5):690-702.

21. Palhares MFS, Schwartz GM. Não é só a torcida organizada: o que os torcedores organizados têm a dizer sobre a violência no futebol? [Internet] [acesso 09/10/2015]. São Paulo: Editora UNESP; 2015.

ENDEREÇO

Diego Luz Moura

Colegiado de Educação Física

Universidade Federal do Vale do São Francisco Av. José de Sá Maniçoba, s/n - Centro 56304-205 - Petrolina - Pernambuco - Brasil e-mail: lightdiego@yahoo.com.br
Recebido para publicação: 09/10/2015

$1^{\text {a }}$ Revisão: 04/07/2017

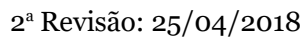

Aceito: 13/06/2018 